\title{
Morfologia de frutos e sementes de Fabaceae ocorrentes em uma área prioritária para a conservação da Caatinga em Pernambuco, Brasil
} Morphology of fruits and seeds of Fabaceae occurring in a priority area for the conservation of Caatinga in Pernambuco, Brazil

\author{
Elisabeth Córdula ${ }^{1,3}$, Marli Pires Morim ${ }^{1} \&$ Marccus Alves ${ }^{2}$
}

\begin{abstract}
Resumo
A família Fabaceae é a mais representativa da Caatinga, compreendendo cerca de um terço da riqueza de espécies catalogadas. Estudos existentes sobre a biodiversidade deste bioma revelam diversas espécies vegetais endêmicas e ameaçadas. Neste sentido, procuramos estabelecer padrões morfológicos para os tipos de frutos, sementes e embriões, com especial enfoque na plúmula, visando possibilitar a identificação de algumas das espécies típicas ou endêmicas da Caatinga. Foram realizadas excursões no período de março de 2006 a março de 2008 para coleta de material botânico em Mirandiba, área prioritária para investigação científica, devido a informações insuficientes sobre sua flora e fauna. Foram selecionadas 16 espécies representando $25 \%$ do total de espécies coletadas na área. Catalogaram-se seis tipos de fruto, onde o tipo padrão foi o legume. As sementes sem pleurograma predominaram da mesma forma que o funículo filiforme e o embrião invaginado com eixo hipocótilo-radícula reto foram os padrões encontrados para estas estruturas. O padrão de plúmula diferenciada em eófilos foi o mais comum. A síndrome de dispersão predominante foi a autocórica seguida pela zoocórica. Os principais diásporos são as sementes, entretanto, os frutos dos tipos legume bacóide, legume nucóide, legume samaróide e sâmara ou ainda o artículo monospérmico do craspédio, podem assumir esta função. Assim como o sucesso na germinação e no estabelecimento de plântulas está associado ao tamanho e quantidade de reservas da semente é bastante provável que o grau de diferenciação da plúmula seja mais um aspecto a ser investigado em relação ao seu papel no êxito do estabelecimento de plântulas.
\end{abstract}

Palavras-chave: dispersão, diversidade, morfologia, plúmula, taxonomia.

\begin{abstract}
Fabaceae is the most representative of the Brazilian Caatinga, comprising about one-third of species richness cataloged. Existing research on the biodiversity of this biome reveal several endemic and endangered plant species. In this sense, we aim to establish standards morphological types of fruits, seeds and embryos, with special focus on plumule, to enable the identification of some of the typical or endemic species of the Caatinga. Tours were conducted from March 2006 to March 2008 to collect botanical material in Mirandiba, priority area for research due to insufficient information on its flora and fauna. We selected 16 species, representing $25 \%$ of total species collected in the area. Were cataloged six types of fruit, where the standard type was the legume. The seeds without pleurogram prevailed, in the same way that the funiculus filiform, invaginated embryo and hypocotyl-radicle axis with straight patterns were found for these structures. The pattern plumule on differentiated eophylls was the most common. The most common dispersion syndrome was the autochory followed by zoochory. The main propagules are seeds, however, the fruits types baccoid pod, camara, samaroid pod and samara or the monospermic article of the craspedium can assume this role. As the successful germination and seedling establishment is associated with the size and quantity of seed reserve is quite likely that the degree of differentiation of the plumule is another aspect to be investigated in relation to their role in the success of seedling establishment.
\end{abstract}

Key words: dispersal, diversity, morphology, plumule, taxonomy.

\footnotetext{
${ }^{1}$ Instituto de Pesquisas Jardim Botânico do Rio de Janeiro, DIPEC, R. Pacheco Leão 915, 22460-030, Rio de Janeiro, RJ, Brasil.

${ }^{2}$ Universidade Federal de Pernambuco, Centro de Ciências Biológicas, Lab. Morfotaxonomia Vegetal, R. Moraes Rego s/n, Cidade Universitária, 50670-901, Recife, PE, Brasil.

${ }^{3}$ Autor para correspondência: ecordula@yahoo.com.br
} 


\section{Introdução}

O domínio da Caatinga apresenta cobertura vegetal xerofítica, muito diversificada por razões climáticas, edáficas, topográficas e antrópicas (Alves et al. 2009). Apresenta taxas elevadas de diversidade taxonômica e de endemismo, fazendose necessário um melhor conhecimento de sua flora para possíveis medidas de conservação de suas áreas (Prado 2003). De acordo com Ministério do Meio Ambiente (MMA 2002), o bioma Caatinga apresenta elevada heterogeneidade vegetacional caracterizada por distintas fisionomias e elevado endemismo, fazendo deste um ambiente de extrema importância biológica.

A escassez de água é um fator limitante na região da Caatinga e para viverem nestas áreas as plantas encontraram diversas adaptações para a sua sobrevivência como a caducifolia do estrato arbóreo-arbustivo e o estrato herbáceosubarbustivo, por sua vez, está presente apenas na estação chuvosa (Queiroz 2009). A caducifolia e as florações rápidas dificultam a identificação das espécies, no entanto, neste estudo foi observado que os frutos e as sementes são persistentes entre as fenofases uma vez que para as angiospermas essas estruturas são pouco influenciadas pelo ambiente. A ecologia de dispersão constitui uma importante base para o entendimento da estrutura e funcionamento das comunidades florestais nos neotrópicos (Gentry 1983), a dispersão das sementes é uma fase importante no ciclo de vida das plantas e o mecanismo de dispersão pode ser um fator determinante na distribuição espacial dos indivíduos adultos no ambiente.

Fabaceae inclui 727 gêneros e 19.327 espécies com distribuição cosmopolita (Lewis et al. 2005). No Brasil ocorrem 212 gêneros nativos e 2.732 espécies, estando entre as famílias mais ricas na maioria dos ecossistemas brasileiros (Lima et al. 2013). Na Caatinga ocorrem 86 gêneros e 320 espécies, constituindo cerca de um terço da riqueza do bioma (Queiroz 2009).

O pericarpo em Fabaceae sofreu vários processos de adaptação (Roth 1977) e além do folículo e do legume, que são predominantes, ocorrem também sâmaras, drupas, núculas, lomentos, craspédios e tipos intermediários (Barroso et al. 1999). As sementes e embriões também podem apresentar características marcantes e, algumas vezes, particulares de Fabaceae. A considerável diversidade na morfologia de frutos, sementes e embriões de Fabaceae tem sido objeto de estudos de especialistas na família, considerando que tais estruturas são, em alguns gêneros, caracteres diagnósticos (Bentham 1875; Burkart 1943; Boelcke 1946; Bravato 1974; Gunn 1984, 1986; Lima 1985; Kirkbride et al. 2003; Meireles \& Tozzi 2008, entre outros). A morfologia de tais estruturas é relevante também em análises relacionadas a adaptações de mecanismos de dispersão (Lima 1990).

Neste contexto o presente trabalho teve como objetivos investigar os padrões morfológicos dos frutos, sementes e embriões das espécies de Fabaceae que ocorrem na área de Caatinga de Mirandiba e propiciar a identificação dos táxons através de tais estruturas.

\section{Material e Métodos}

Mirandiba é uma área prioritária para investigação científica devido a informações insuficientes sobre sua flora e fauna (MMA 2002). Situa-se no estado de Pernambuco $\left(08^{\circ} 13^{\prime}\right.$ 'S e $38^{\circ} 43^{\prime} \mathrm{W}$ ), a $550 \mathrm{~m}$ de altitude e cerca de $500 \mathrm{~km}$ do Recife. Sua área ocupa aproximadamente $800 \mathrm{~km}^{2}$.

As expedições de campo para observações e coletas dos espécimes foram realizadas entre março de 2006 e março de 2008. A identificação do material botânico seguiu os métodos descritos em Córdula et al. (2008), por ocasião do levantamento florístico realizado na área em estudo.

Os frutos e as sementes foram acondicionados em sacos de papel e colocados na estufa para desidratação. As amostras foram tombadas no acervo do Herbário Professor Geraldo Mariz (UFP) da Universidade Federal de Pernambuco, com duplicatas nos herbários HUEFS e RB. Nos casos em que os frutos e/ou as sementes foram escassos para a análise, recorreu-se ao acervo do RB, sendo estes exemplares citados como material adicional.

Adotou-se a classificação de subfamílias e tribos de Fabaceae apresentada por Lewis et al. (2005). As espécies tratadas foram selecionadas com base no levantamento florístico realizado em Mirandiba (Córdula et al. 2008) e na citação destes táxons como típicos ou endêmicos da Caatinga, segundo Queiroz (2002, 2006 e 2009) e Cardoso \& Queiroz (2007). Dahlstedtia araripensis (Benth.) M.J.Silva \& A.M.G.Azevedo foi incluída no estudo, embora sua distribuição geográfica tenha sido ampliada, em virtude de revisão realizada por Silva et al. (2012).

Os conceitos e a terminologia adotados no presente trabalho estão baseados em: Barroso et al. 
(1999) para os tipos de fruto; Corner (1976) para os tipos de semente; Duke (1969), Lima (1985) e Oliveira (1999) para os tipos de plúmulas. As formas descritas para os frutos e as sementes foram baseadas em Stern (1980) e Harris \& Harris (2000). A determinação das síndromes de dispersão e dos diásporos seguiu Van Der Pijl (1982).

Para a descrição morfológica foram considerados frutos e sementes maduras, as quais foram hidratadas em água destilada, de modo a facilitar a remoção do tegumento e do endosperma, quando presente; àquelas com tegumento impermeável foram escarificadas mecanicamente antes da hidratação.

Além da classificação dos tipos de frutos, estes foram descritos em relação à forma, o tamanho, consistência do pericarpo e quantidade de sementes. As sementes foram observadas quanto ao tamanho, considerando-se como base o hilo (Lima 1985), a forma, superfície da testa, presença e tamanho do pleurograma (apical-basal, ocupa mais de $2 / 3$ do comprimento da semente e mediano, quando ocupa menos de $1 / 3$ ), tamanho do funículo (rudimentar $\leq 1$ $\mathrm{mm}$, curto $\leq 5 \mathrm{~mm}$ e longo $>5 \mathrm{~mm}$ ), forma do hilo e a presença de endosperma. A descrição do embrião baseou-se na forma, na posição do eixo hipocótiloradícula em relação aos cotilédones e na plúmula. Os tipos de plúmulas mencionados nas descrições foram baseados nas seguintes definições: plúmula indiferenciada ou rudimentar - eixo hipocótiloradícula sem diferenciação aparente de primórdios foliares, ou estes muito rudimentares; plúmula diferenciada em primórdios foliares (eófilos) - eixo hipocótilo-radícula diferenciado em primórdios foliares na forma de segmentos ou em eófilos evidentes, segmentados ou não nas margens; algumas espécies com apêndices adjacentes (estípulas).

\section{Resultados}

O estudo da composição florística em Mirandiba resultou em 83 espécies de Fabaceae, distribuídas em 42 gêneros (Córdula et al. 2009). Neste estudo observou-se que 16 espécies eram endêmicas da Caatinga, sendo, portanto escolhidas para uma análise mais aprofundada da morfologia dos frutos (Fig. 1), sementes (Fig. 2) e embriões (Fig. 3).

\section{Chave para identificação das espécies de acordo com a morfologia do fruto e da semente}

1. Fruto legume.

2. Fruto com valvas divergentes após a deiscência ou com valvas enroladas em espiral antes ou após a deiscência; funículo espessado e curto.

3. Fruto com valvas divergentes após a deiscência; semente com testa maculada; embrião parcialmente criptorradicular

8. Calliandra depauperata

3'. Fruto com valvas enroladas em espiral após a deiscência; semente com testa sem máculas; embrião invaginado.

4. Fruto com valvas enroladas em espiral antes da deiscência; semente com arilo vermelho 9. Pithecellobium diversifolium

4'. Fruto com valvas planas antes da deiscência; sementes sem arilo vermelho.

5. Fruto com 1-2 cm de largura; semente com testa não foveolada.

6. Pleurograma presente; embrião criptorradicular .... 7. Senegalia piauhiensis

6'. Pleurograma ausente; embrião invaginado ...... 2. Poincianella gardneriana

5. Fruto com até $0,5 \mathrm{~cm}$ de largura; semente com testa foveolada.

7. Fruto com 2-3,5 cm de compr., 5-7 sementes, obovadas; plúmula indiferenciada 3. Chamaecrista amiciella

7’. Fruto com 5-6 cm de compr., 18-22 sementes, subquadrangulares; plúmula diferenciada em eófilos

4. Chamaecrista duckeana

2'. Fruto com valvas planas antes e após a deiscência; funículo filiforme e longo.

8. Semente com pleurograma.

9. Semente linear-oblonga, angulosa, rafe pronunciada; plúmula indiferenciada 6. Senna trachypus

9'. Semente obovada a suborbicular, rafe não pronunciada; plúmula diferenciada em eófilos 12. Piptadenia stipulacea

8'. Semente sem pleurograma. 
10. Fruto oblongo; $12-16$ sementes aladas

11. Parapiptadenia zehntneri

10'. Fruto elíptico; 1 semente globosa 16. Trischidium molle

1'. Fruto de outro tipo.

11. Fruto sâmara ou legume samaroide; semente com hilo mediano ou sub-mediano.

12. Fruto sâmara; hilo submediano 15. Luetzelburgia auriculata

12'. Fruto legume samaroide; hilo mediano 13. Dahlstedia araripensis

11'. Fruto de outro tipo; semente com hilo terminal ou subterminal.

13. Fruto craspédio 10. Mimosa ophtalmocentra

13'. Fruto legume bacoide ou legume nucoide.

14. Fruto legume bacoide.

15. Fruto cilíndrico, endocarpo coriáceo; semente com linhas de fratura reticuladas centrais; plúmula indiferenciada 5. Senna macranthera var. pudibunda

15'. Fruto oblongo, endocarpo lenhoso; semente com linhas de fratura ausentes; plúmula diferenciada em eófilos 1. Libidibia ferrea var. ferrea 14'. Fruto legume nucoide 14. Dioclea grandiflora

\section{Subfamília Caesalpinioideae}

O padrão de fruto é o legume, exceto em Libidibia ferrea (Mart. ex Tul.) L.P. Queiroz var. ferrea e Senna macranthera (Coll.) H.S.Irwin \& Barneby var. pudibunda (Benth.) H.S. Irwin \& Barneby que é um legume bacoide. Os frutos são estipitados, exceto nas espécies de Chamaecrista; a superfície é geralmente reticulada. As sementes, em sua maioria, não são pleurogramáticas; a região hilar é terminal a subterminal, o funículo é espessado e curto e a testa é rígida; o endosperma está presente, exceto em Chamaecrista duckeana (P. Bezerra \& Afr. Fern.) H.S. Irwin \& Barneby. O embrião é axial e invaginado, o eixo hipocótilo-radícula é reto; apresenta plúmula indiferenciada, exceto em Chamaecrista duckeana, Libidibia ferrea var. ferrea e Poincianella gardneriana (Benth.) L.P. Queiroz, que tem a plúmula diferenciada em eófilos.

1. Libidibia ferrea (Mart. ex Tul.) L.P. Queiroz var. ferrea, Legum. Caatinga 130. 2009.

Figs. 2f, 3n-p

Legume bacoide, 9-10 × 3-3,5 cm, oblongo, ápice acuminado, base atenuada, margem inteira, irregularmente constrita, superfície lisa, pubérula; mesocarpo pulposo, rico em tanino; endocarpo lenhoso, individualizado em câmaras monospérmicas. Sementes 9-13, 10-12 × 7-8 mm, obovado-elípticas, marrons; funículo filiforme, longo. Embrião com plúmula diferenciada em eófilos, emergências glandulares presentes. Dispersão zoocórica, na qual o diásporo é o fruto. Material examinado: Mirandiba, 30.III.2006, E. Córdula et al. 10 (UFP); 3.X.2006, E. Córdula et al. 188 (UFP).
2. Poincianella gardneriana (Benth.) L.P. Queiroz, Legum. Caatinga 123. $2009 . \quad$ Fig. 21

Legume, 7-9 × 1,5-2 cm, subfalcado, ápice rostrado, base obtusa, margem inteira, contínua, superfície pubescente; endocarpo esponjoso, sublenhoso; valvas planas, enrolando em espiral após a deiscência. Sementes 3-5, 10-11 × $10 \mathrm{~mm}$, obovado-oblongas, marrons, testa lisa, linhas de fratura reticuladas na porção central. Embrião com cotilédones conspicuamente nervados, plúmula diferenciada em eófilos, emergências glandulares presentes. Dispersão autocórica, na qual o diásporo é a semente.

Material examinado: Mirandiba, 23.VI.2007, E. Córdula et al. 306 (HUEFS, RB, UFP).

Material adicional: BRASIL. RIO DE JANEIRO: Rio de Janeiro: Arboreto do Jardim Botânico do Rio de Janeiro, 9.VI.1999, M.D. Campos 115 (RB).

3. Chamaecrista amiciella (H.S.Irwin \& Barneby) H.S.Irwin \& Barneby, Mem. New York Bot. Gard. 35: 661. 1982.

Fig. $2 \mathrm{j}$

Legume, $2-3,5 \times 0,5 \mathrm{~cm}$, oblongo, ápice acuminado, base obtusa, não estipitado, margem inteira, contínua, superfície granulosa, pubescente; valvas planas, enroladas em espiral após a deiscência. Sementes 5-7, 3-4 × $3 \mathrm{~mm}$, obovadas, negras, testa densamente foveolada. Embrião com plúmula indiferenciada. Dispersão autocórica, na qual o diásporo é a semente.

Material examinado: 18.IV.2007, E. Córdula et al. 250 (HUEFS, RB, UFP).

4. Chamaecrista duckeana (P. Bezerra \& Afr. Fern.) H.S. Irwin \& Barneby, Mem. New York Bot. Gard. 35:861. 1982.

Figs. 2h, 3g-i

Legume, 5-6 × 0,4-0,5 cm, linear-oblongo, ápice acuminado, base atenuada, não estipitado, 


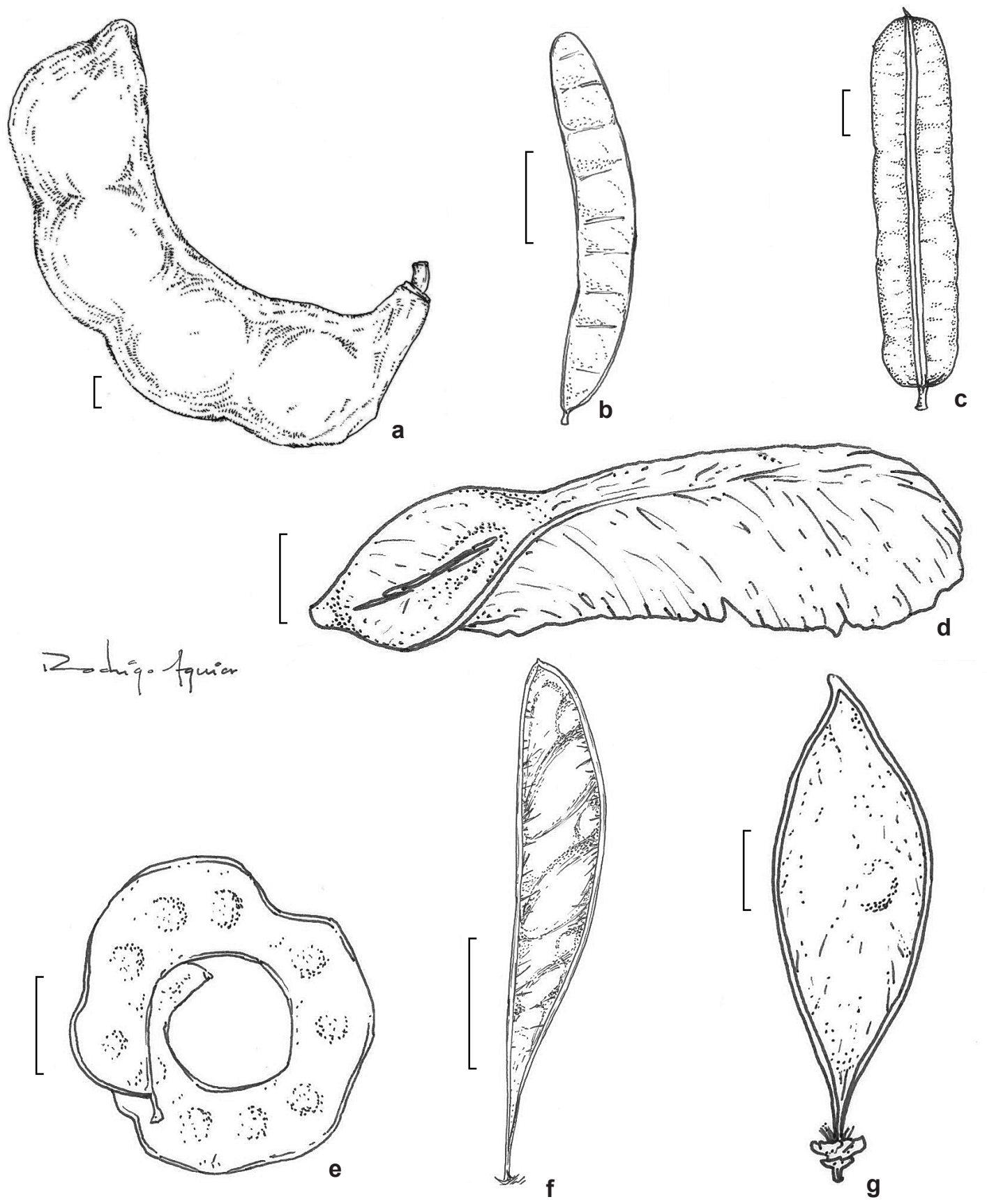

Figura 1 - Frutos - a. Dioclea grandiflora - legume nucoide (E. Córdula 267). b. Mimosa ophthalmocentra - craspédio (M. Oliveira 2862). c. Senna macranthera var. pudibunda - legume bacóide (E. Córdula 307). d. Luetzelburgia auriculata - sâmara (E. Córdula 211). e. Pithecellobium diversifolium - legume (E. Córdula 196). f. Calliandra depauperata - legume (G.P. Lewis 1132). g. Dahlstedtia araripensis - legume samaróide (E. Córdula 205). Escala $=1 \mathrm{~cm}$.

Figure 1 - Fruits - a. Dioclea grandiflora - nuccoid pod (E. Córdula 267). b. Mimosa ophthalmocentra - craspedium (M. Oliveira 2862). c. Senna macranthera var. pudibunda - baccoid pod (E. Córdula 307). d. Luetzelburgia auriculata - samara (E. Córdula 211). e. Pithecellobium diversifolium - legume (E. Córdula 196). f. Calliandra depauperata - legume (G.P. Lewis 1132). g. Dahlstedtia araripensis - samaroid pod (E. Córdula 205). Scale $=1 \mathrm{~cm}$. 

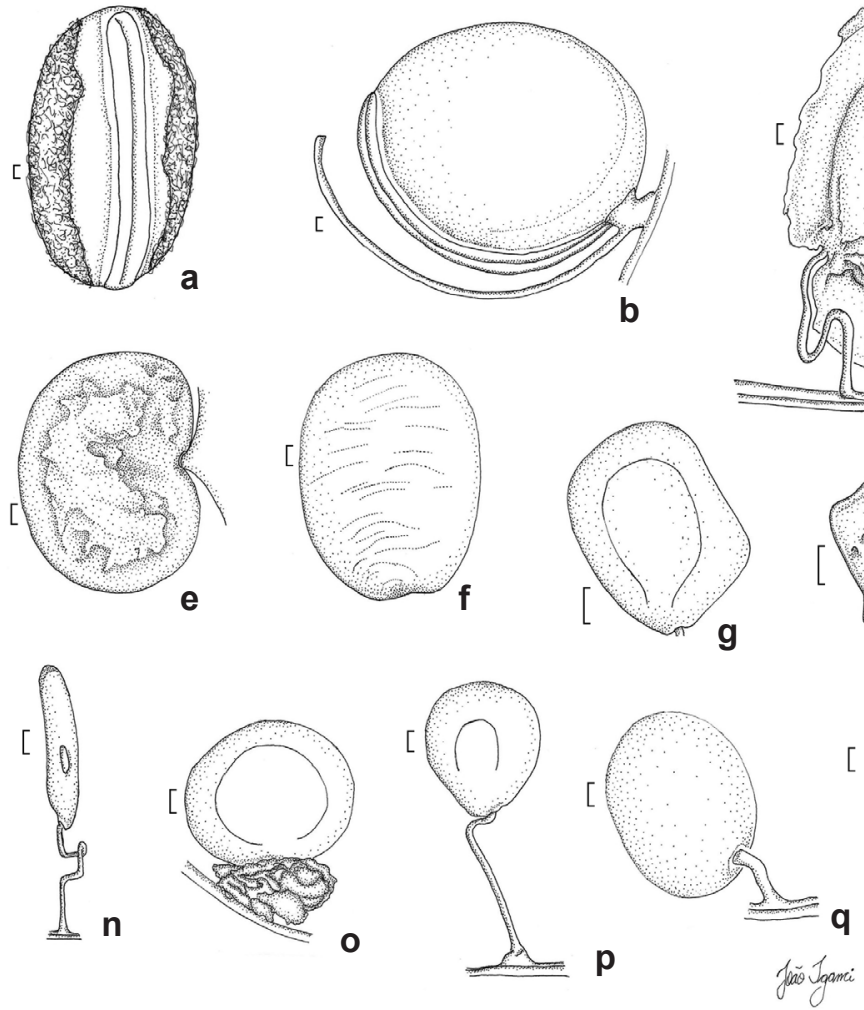

C
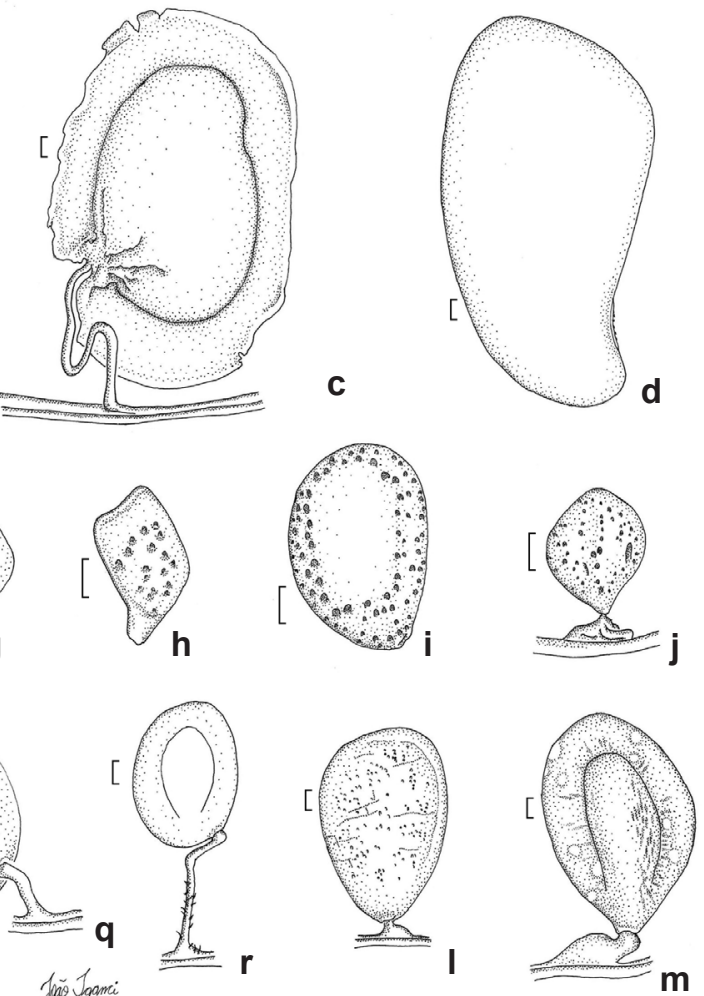

Figura 2 - Sementes - a-b. Dioclea grandiflora - a. semente com endocarpo aderido; b. detalhe do funículo linguiforme (E. Córdula 267). c. Parapiptadenia zehntneri - detalhe do funículo filiforme e longo (E. Córdula 203). d. Luetzelburgia auriculata, semente (E. Córdula 211). e. Dahlstedtia araripensis - detalhe do funículo rudimentar (E. Córdula 205). f. Libidibia ferrea var. ferrea-semente (E. Córdula 10). g. Mimosa ophthalmocentra, semente (M. Oliveira 2862). h. Chamaecrista duckeana - detalhe da testa foveolada (E. Córdula 233). i. Senna macranthera var. pudibunda, detalhe da testa com linhas de fratura centrais e fovéolas (E. Córdula 307). j. Chamaecrista amiciella, detalhe da testa densamente foveolada e do funículo espessado e curto (E. Córdula 250). 1. Poincianella gardneriana - detalhe das linhas de fratura reticuladas centrais e do funículo espessado e curto (M.D. Campos 115). m. Calliandra depauperata, detalhe do pleurograma apical-basal e do funículo espessado e curto (G.P. Lewis 1132). n. Senna trachypus, detalhe do pleurograma submediano e funículo filiforme e longo (E. Córdula 81). o. Pithecellobium diversifolium, detalhe do pleurograma apical-basal e do arilo (E. Córdula 196). p. Piptadenia stipulacea - detalhe do pleurograma mediano e do funículo filiforme e longo (E. Córdula 194). q. Trischidium molle - detalhe do funículo filiforme e longo (E. Córdula 214). r. Senegalia piauhiensis - detalhe do pleurograma apical-basal e do funículo filiforme e longo (D. Moura 1067). Escala $=1 \mathrm{~mm}$.

Figure 2 - Seeds - a-b. Dioclea grandiflora - a. seed with endocarp acceded; b. detail of the linguiform funiculus (E. Córdula 267). c. Parapiptadenia zehntneri - detail of the filiform and long funiculus (E. Córdula 203). d. Luetzelburgia auriculata (E. Córdula 211). e. Dahlstedtia araripensis - detail of rudimentary funiculus (E. Córdula 205). f. Libidibia ferrea var. ferrea (E. Córdula 10). g. Mimosa ophthalmocentra (M. Oliveira 2862). h. Chamaecrista duckeana - detail of foveolate testa (E. Córdula 233). i. Senna macranthera var. pudibunda, detail of testa with central fracture lines and foveola (E. Córdula 307). j. Chamaecrista amiciella - detail of densely foveolate testa; thickened and short funiculus (E. Córdula 250). 1. Poincianella gardneriana - detail of the central crosslinked fracture lines; thickened and short funiculus (M.D. Campos 115). m. Calliandra depauperata - detail of apical-basal pleurogram; thickened and short funiculus (G.P. Lewis 1132). n. Senna trachypus - detail of sub-median pleurogram; filiform and long funiculus (E. Córdula 81). o. Pithecellobium diversifolium - detail of apical-basal pleurogram; the aryl (E. Córdula 196). p. Piptadenia stipulacea - detail of median pleurogram; filiform and long funiculus (E. Córdula 194). q. Trischidium molle - detail of the filiform and long funiculus (E. Córdula 214). r. Senegalia piauhiensis - detail of apical-basal pleurogram; filiform and long funiculus (D. Moura 1067). Scale $=1 \mathrm{~mm}$. 

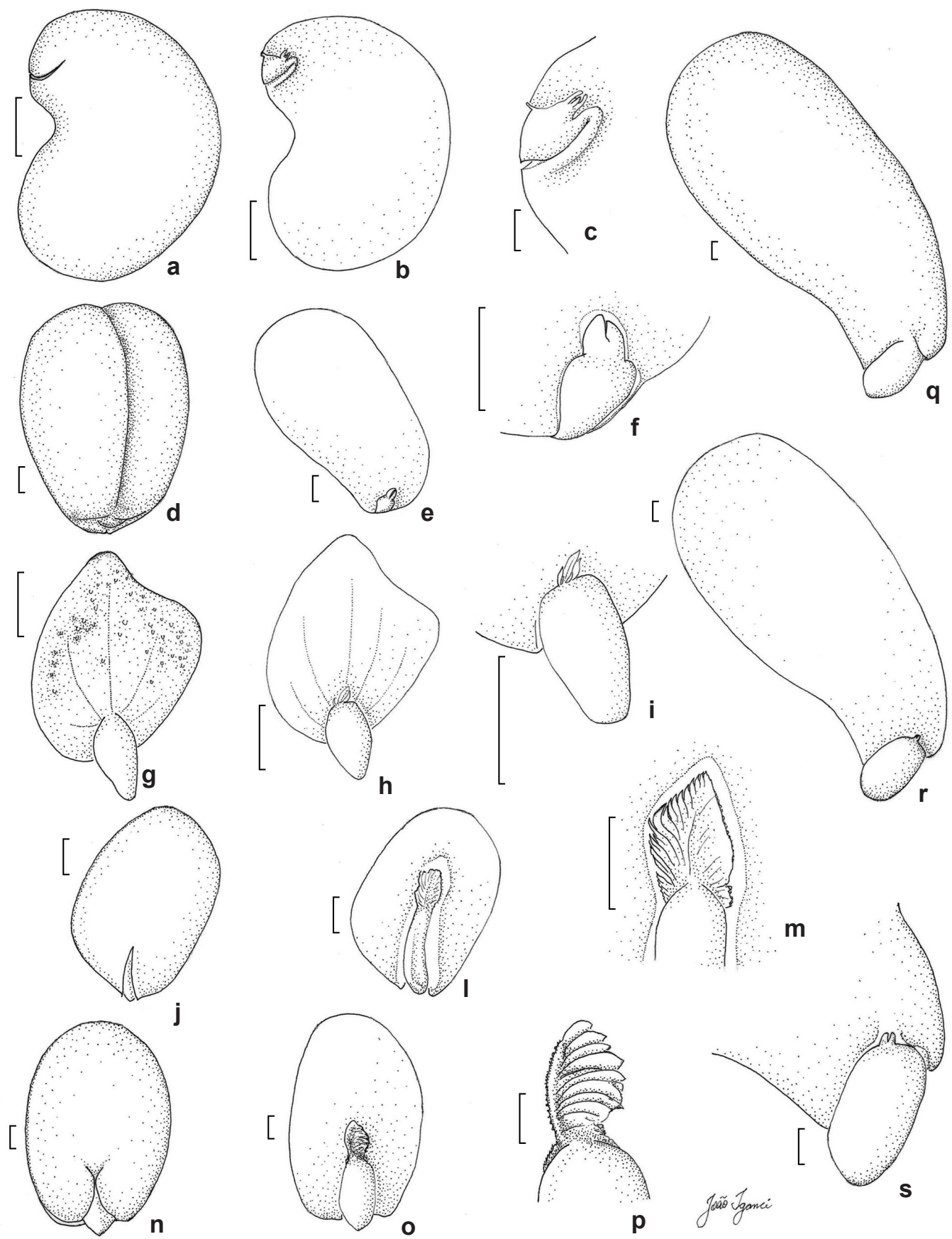

[
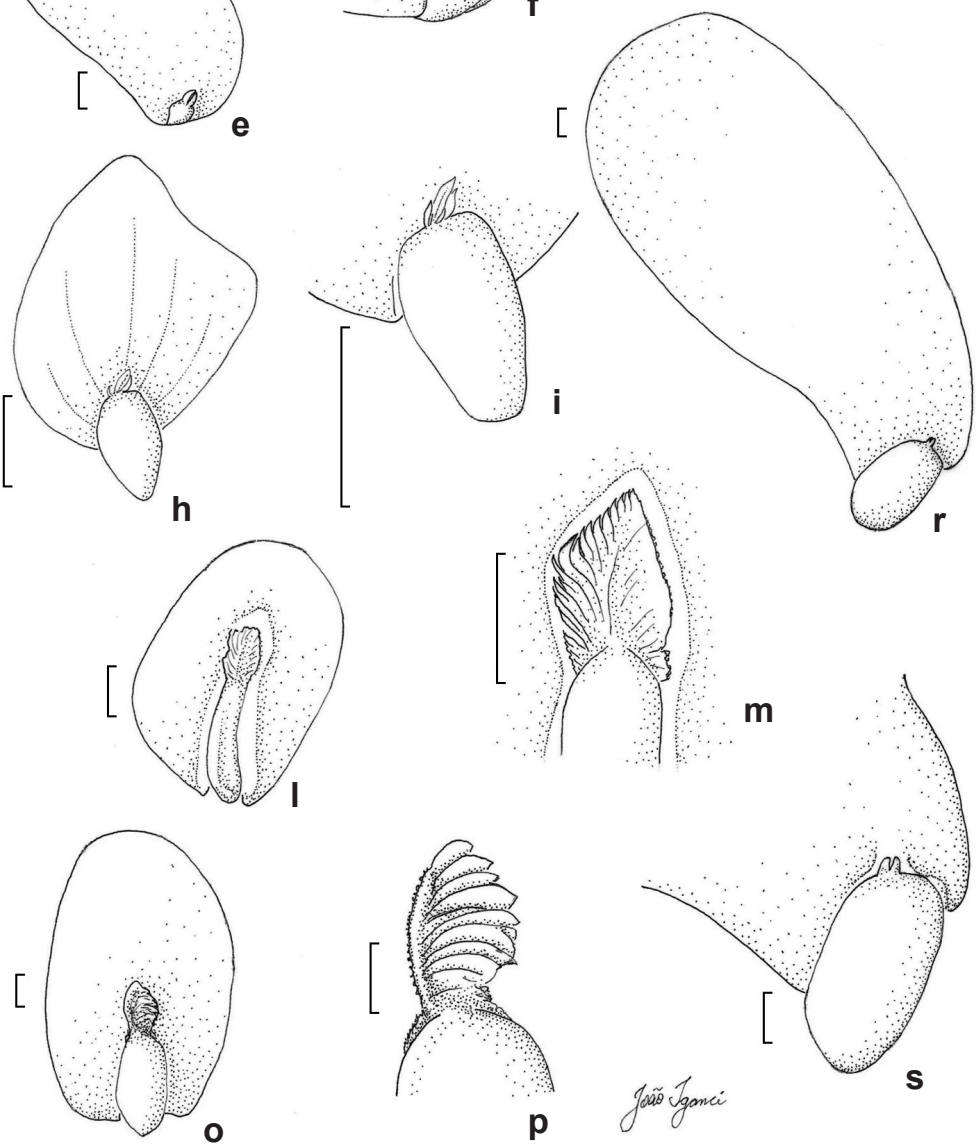

$\mathbf{m}$

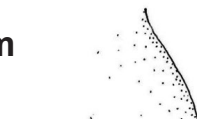

p

Figura 3 - Embriões - a-c. Dahlstedtia araripensis - a. embrião; b. embrião em secção longitudinal; c. detalhe da plúmula (E. Córdula 205). d-f. Trischidium molle - d. embrião; e. embrião em secção longitudinal; f. detalhe da plúmula (E. Córdula 214). g-i. Chamaecrista duckeana - g. embrião; h. embrião em secção longitudinal; i. detalhe da plúmula (E. Córdula 233). j-m. Calliandra depauperata - j. embrião, 1. embrião em secção longitudinal, m. detalhe da plúmula (G. P. Lewis 1132). n-p. Libidibia ferrea var. ferrea - n. embrião; o. embrião em secção longitudinal; p. detalhe da plúmula (E. Córdula 10). q-s. Luetzelburgia auriculata, -q. embrião; r. embrião em secção longitudinal; s. detalhe daplúmula (E. Córdula 211). Escala =1 mm. Figure 3 - Embryos - a-c. Dahlstedtia araripensis - a. embryo; b. embryo in longitudinal section; c. detail of the plumule (E. Córdula 205). d-f. Trischidium molle - d. embryo; e. embryo in longitudinal section; f. detail of the plumule (E. Córdula 214). g-i. Chamaecrista duckeana - g. embryo; h. embryo in longitudinal section; i. detail of the plumule ( $E$. Córdula 233). j-m. Calliandra depauperata -j. embryo; 1 . embryo in longitudinal section; $\mathrm{m}$. detail of the plumule (G.P. Lewis 1132). n-p. Libidibia ferrea var. ferrea - n. embryo; o. embryo in longitudinal section, p. detail of plumule (E. Córdula 10); q-s. Luetzelburgia auriculata - q. embryo; r. embryo in longitudinal section, s. detail of the plumule (E. Córdula 211). Scale = $1 \mathrm{~mm}$. 
margem inteira, contínua, superfície glabrescente; valvas planas, enroladas em espiral após a deiscência. Sementes 18-22, 3,5-4,5 × 2,5-3 mm, subquadrangulares com ápice invaginado, base oblíqua, marrons, testa foveolada; endosperma ausente. Embrião com plúmula diferenciada em eófilos. Dispersão autocórica, na qual o diásporo é a semente.

Material examinado: 17.IV.2007, fl.e fr., E. Córdula et al. 233 (HUEFS, RB, UFP).

5. Senna macranthera (Coll.) H.S.Irwin \& Barneby var. pudibunda (Benth.) H.S. Irwin \& Barneby, Mem. New York Bot. Gard. 35(1): 186. 1982.

Figs. 1c, $2 \mathrm{i}$

Legume bacoide, 5-8 $\times 1-1,5 \mathrm{~cm}$, cilíndrico, ápice acuminado, base obtusa, margem contínua, superfície glabra, mesocarpo pulposo, viscoso, endocarpo coriáceo, com câmaras monospérmicas. Sementes 50-60, biseriadas, 5-7 × 3-4 mm, oblongo-ovadas, marrons, linhas de fratura reticuladas centrais, fovéolas circundando as linhas de fratura. Embrião com plúmula indiferenciada. Dispersão zoocórica, na qual o diásporo é o fruto. Material examinado: 22.VI.2007, E. Córdula et al. 305 (HUEFS, UFP); 23.VI.2007, E. Córdula et al. 307 (UFP).

6. Senna trachypus (Benth.) H.S. Irwin \& Barneby, Mem. New York Bot. Gard. 35: 509. 1982.

Fig. 2n

Legume, 7-9 × 1,2-1,4 cm, oblongo, ápice acuminado, base atenuada, margem inteira, aliforme, irregularmente constrita, superfície pubescente; valvas planas. Sementes 30-60, 6-7 × $1-1,5 \mathrm{~mm}$, linear-oblongas, angulosas, amareladas, testa esfoliante, rafe pronunciada, pleurograma submediano; funículo filiforme, longo. Embrião com plúmula indiferenciada. Dispersão autocórica, na qual o diásporo é a semente.

Material examinado: 31.V.2006, E. Córdula et al. 81 (UFP); 19.VI.2007, E. Córdula et al. 273 (RB, UFP).

\section{Subfamília Mimosoideae}

O padrão de fruto é o legume, estipitado, com exceção de Mimosa ophtalmocentra Mart. ex Benth. que é um craspédio, não estipitado. A superfície é geralmente reticulada e ondulada. As sementes são pleurogramáticas, com o pleurograma apical-basal, exceto em Parapiptadenia zehntneri (Harms) M.P. Lima \& H.C. Lima. A região hilar é subterminal, o funículo é filiforme e longo, com exceção de Calliandra depauperata Benth. e
Pithecellobium diversifolium Benth. A testa é lisa, nítida e rígida; o endosperma está ausente, exceto em Mimosa ophtalmocentra, Parapiptadenia zehntneri e Piptadenia stipulacea (Benth.) Ducke. O embrião é axial, invaginado ou criptorradicular com eixo hipocótilo-radícula reto e plúmula diferenciada em eófilos, exceto em Mimosa ophtalmocentra que é indiferenciada. Síndromes e Unidades de Dispersão: geralmente autocórica. Anemocórica em Parapiptadenia zehntneri e zoocórica em Pithecellobium diversifolium. O diásporo é sempre a semente, exceto em Mimosa ophtalmocentra, que é o artículo monospérmico.

7. Senegalia piauhiensis (Benth.) A. Bocage \& L.P. Queiroz, Neodiversity 1: 12. $2006 . \quad$ Fig. 2r Legume, 12-16 × 1,2-1,4 mm, linear, ápice agudo, base atenuada, margem inteira, espessada, superfície com nervuras conspícuas, tomentosa, granulosa; pericarpo cartáceo, conspicuamente reticulado; valvas planas, enrolando em espiral após a deiscência. Sementes 9-13, 5-6 × 4,5-4,8 $\mathrm{mm}$, suborbiculares, levemente marginadas, marrom-avermelhadas. Embrião criptorradicular. Dispersão autocórica, na qual o diásporo é a semente.

Material examinado: Mirandiba, 9.II.2007, E. Córdula et al. 212 (UFP).

Material adicional: BRASIL. ALAGOAS: Olho D'água do Casado, 1.III.2000, D. Moura 1067 (RB).

8. Calliandra depauperata Benth., Trans. Linn. Soc. London 30(3): 546. $1875 . \quad$ Figs. 1f, 2m, 3j-m

Legume 3-4,5 × 0,6-0,7 mm, oblanceolado, ápice acuminado, base atenuada, margem inteira, espessada, superfície pubescente, pericarpo rígido-cartáceo; funículo espessado, curto; valvas divergentes após a deiscência. Sementes 4-8, 5 $\times$ 3-3,5 mm, elípticas, testa maculada. Embrião parcialmente criptorradicular; plúmula diferenciada em eófilos, com tricomas glandulares. Dispersão autocórica, na qual o diásporo é a semente.

Material examinado: Mirandiba, 31.V.2006, E. Córdula et al. 89 (HUEFS, UFP).

Material adicional: BRASIL. PIAUÍ: São Raimundo Nonato, 20.I.1982, G. P. Lewis 1132 (RB).

9. Pithecellobium diversifolium Benth., London J. Bot. 3: 201. $1844 . \quad$ Figs. 1e, 2o

Legume, 8-12 × 1-1,5 cm, espiralado, ápice arredondado, base atenuada, margem inteira, espessada, superfície glabrescente, pericarpo cartáceo; semente com arilo vermelho, hilo 
submediano; valvas enroladas em espiral após a deiscência. Sementes 7-13, 7-8 mm, orbiculares, pretas. Embrião criptorradicular. Dispersão zoocórica, na qual o diásporo é a semente.

Material examinado: Mirandiba, 4.X.2006, E. Córdula et al. 196 (UFP); 10.II.2007, fl., E. Córdula et al. 208 (HUEFS, RB, UFP).

10. Mimosa ophthalmocentra Mart. ex Benth., Trans. Linn. Soc. London 30: 415. 1875.

Figs. 1b, 2g

Craspédio, 5-6,5 × 0,8-1 cm, oblanceolado, ápice obtuso, base obtusa, réplum levemente sinuoso, superfície granulosa, pubescente, pericarpo sublenhoso. Sementes 7-10, $6 \times 4 \mathrm{~mm}$, sub-quadrangulares, marrons, linhas de fratura reticuladas centrais; endosperma gelatinoso, aderido à testa. Embrião invaginado, eixo obliquo em relação ao comprimento dos cotilédones; plúmula indiferenciada. Dispersão autocórica, na qual o diásporo é o artículo monospérmico.

Material examinado: Mirandiba, 18.IV.2007, J. Silva et al. 193 (HUEFS, UFP).

Material adicional: BRASIL. BAHIA: Nova Glória, 15.VI.2007, M. Oliveira et al. 2862 (UFP).

11. Parapiptadenia zehntneri (Harms) M. P. Lima \& H. C. Lima, Rodriguésia 36(60): 26. 1984.

Fig. 2c

Legume, $12-16 \times 2-2,5 \mathrm{~cm}$, oblongo, ápice acuminado, base atenuada, margem inteira, irregularmente constrita, superfície lenticelada, glabra, pericarpo rígido-cartáceo; valvas planas. Sementes 12-16, 15-20 × 8-12 mm, transversoelípticas, marrons, testa membranácea, alada, pleurograma ausente; endosperma inconspícuo. Embrião parcialmente invaginado. Dispersão anemocórica, na qual o diásporo é a semente.

Material examinado: Mirandiba, 7.II.2007, E. Córdula et al. 203 (HUEFS, RB, UFP); 10.II.2007, K. Pinheiro et al. 62 (UFP).

12. Piptadenia stipulacea (Benth.) Ducke, Arq. Jard. Bot. Rio de Janeiro 5: 126. $1930 . \quad$ Fig. 2p

Legume, 5-10 × 1,8-2,2 cm, oblongo, ápice acuminado, base arredondada, margem inteira, levemente sinuosa, superfície glabrescente, pericarpo cartáceo; valvas planas. Sementes 5-10, 6-7 × 5-6 mm, obovadas, marrons, pleurograma mediano; endosperma espesso, aderido à testa. Embrião invaginado. Dispersão autocórica, na qual o diásporo é a semente.

Material examinado: Mirandiba, 4.X.2006, E. Córdula et al. 194 (HUEFS); 22.VI.2007, E. Córdula et al. 302 (UFP).
Subfamília Papilionoideae

Neste grupo observou-se uma maior variedade de tipos de frutos. Todos são estipitados, exceto em Dioclea grandiflora Mart. ex Benth., com superfície reticulada e margem constrita entre as sementes. As sementes não apresentam pleurograma, a região hilar é mediana a submediana, o hilo é geralmente elíptico, o funículo é espessado, a testa é rígida e o endosperma está ausente. O embrião é axial e invaginado, com o eixo hipocótilo-radícula papilionoide, plúmula indiferenciada, exceto em Trischidium molle (Benth.) H.E. Ireland e Dahlstedia araripensis (Benth.) M.J. Silva \& A.M.G. Azevedo, que é diferenciada em eófilos.

Síndromes e Unidades de Dispersão: são plantas autocóricas onde o diásporo pode ser a semente ou o fruto, anemocóricas tendo o fruto como diásporo ou zoocóricas na qual o diásporo é a semente.

13. Dahlstedia araripensis (Benth.) M. J. Silva \& A. M. G. Azevedo, Taxon 61(1): 104. 2012.

Figs. 1g, 2e, 3a-c

Legume samaroide, $6-10 \times 1,5-2 \mathrm{~cm}$, elíptico, ápice acuminado, base atenuada, margem inteira, contínua, nervura dorsal espessada, superfície glabra, pericarpo cartáceo. Sementes $1-2,1-1,5 \times 1,8-2 \mathrm{~cm}$, reniformes, maculadas, funículo rudimentar. Embrião com eixo hipocótiloradícula curto em relação aos cotilédones; plúmula diferenciada em eófilos. Dispersão anemocórica, na qual o diásporo é o fruto.

Material examinado: Mirandiba, 7.II.2007, E. Córdula et al. 205 (HUEFS, RB, UFP).

Material adicional: BRASIL. PIAUÍ: Picos, 25.III.1973, F.B. Ramalho 267 (RB).

14. Dioclea grandiflora Mart. ex Benth., Comm. Legum. Gen. 68. $1837 . \quad$ Figs. 1a, 2a-b

Legume nucoide, $14-22 \times 4-5,5 \mathrm{~cm}$, oblongo, ápice obtuso, base obtusa, margem inteira, constrita apenas na margem ventral, superfície pilosa, canescente; pericarpo lenhoso, mesocarpo esponjoso, endocarpo aderido à semente. Sementes $3-5,2-2,3 \times 2,3-2,5 \mathrm{~cm}, 1,4-1,9 \mathrm{~cm}$ de espessura, orbiculares, marrons; testa córnea; semente hilar (com hilo linear e semicircundante), funículo linguiforme, longo. Embrião com cotilédones crassos, fortemente aderidos, eixo hipocótiloradícula curto em relação aos cotilédones. Dispersão autocórica, na qual o diásporo pode ser o fruto ou a semente. 
Material examinado: Mirandiba, 10.II.2007, E. Córdula et al. 267 (UFP).

15. Luetzelburgia auriculata (Allemão) Ducke, Notizbl. Bot. Gart. Berlin-Dahlem 11(107): 584. 1932.

Figs. 1d, 2d, 3q-s

Sâmara, 6-7 × 2-2,5 cm, ala reticulada e crenada, núcleo seminífero basal com alas diminutas, ápice acuminado, base obtusa, superfície pilosa, pericarpo cartáceo. Semente-1, 16-20 × 9-12 mm, obovada, subrreniforme, castanho claro, hilo reentrante na região submediana, funículo curto. Dispersão anemocórica, na qual o diásporo é o fruto.

Material examinado: Mirandiba, 9.II.2007, E. Córdula et al. 211 (HUEFS, RB, UFP).

16. Trischidium molle (Benth.) H.E. Ireland, Kew Bull. 62(2): 336. 2007.

Figs. 2q, 3d-f

Legume, 1,7-2 × 1-1,5 cm, elíptico, ápice acuminado, base obtusa, superfície glabra, pericarpo cartáceo; valvas convexas. Semente-1, 6-8 $\times 6-10 \mathrm{~mm}$, globosa, vermelho-escura, camada interna da testa alaranjada; hilo circular, funículo filiforme, longo. Embrião com eixo hipocótiloradícula curto em relação aos cotilédones, plúmula diferenciada em eófilos. Dispersão zoocórica, na qual o diásporo é a semente.

Material examinado: Mirandiba, 31.III.2006, E. Córdula et al. 48 (UFP); 9.II.2007, E. Córdula et al. 214 (HUEFS, RB, UFP).

\section{Discussão e Conclusões}

Para as 16 espécies estudadas foram registrados seis tipos de fruto, sendo que o mais frequente foi o legume, encontrado em cerca de $60 \%$ das espécies. Os demais tipos encontrados foram legume nucoide, legume bacoide, legume samaroide, sâmara e craspédio.

As sementes sem pleurograma predominaram em $75 \%$ das espécies, da mesma forma que o funículo filiforme e o embrião invaginado com eixo hipocótilo-radícula reto foram os padrões encontrados para estas estruturas. Embrião do tipo criptorradicular foi observado apenas na subfamília Mimosoideae. O padrão de plúmula diferenciada em eófilos foi o mais comum entre as espécies estudadas.

A síndrome de dispersão mais frequente (56,25\% das espécies) é a autocórica, seguida pela zoocórica ( $25 \%$ das espécies) e a síndrome anemocórica, que ocorre em um número menor de espécies (18,75\% das espécies). Os principais diásporos são as sementes, entretanto, os frutos dos tipos legume bacoide, legume nucoide, legume samaroide e sâmara ou ainda o artículo monospérmico do craspédio, podem assumir esta função (Tab. 1). Todas as espécies estudadas obtiveram o pico de frutificação na estação seca (Córdula et al. 2009), quando as espécies autocóricas e anemocóricas se disseminam com maior vigor na Caatinga. Como suposto que

Tabela 1 - Padrões de frutos, sementes, embriões, síndromes de dispersão e diásporos das espécies estudadas. Table 1 - Patterns of fruits, seeds, embryos, dispersal syndromes and propagules of the species studied.

\begin{tabular}{|c|c|c|c|c|c|c|c|c|}
\hline Espécie & $\begin{array}{c}\text { Fruto } \\
\text { (Barroso et } \\
\text { al. 1999) }\end{array}$ & Funículo & Pleurograma & Endosperma & Embrião & Plúmula & $\begin{array}{l}\text { Síndrome de } \\
\text { dispersão }\end{array}$ & Diásporo \\
\hline $\begin{array}{l}\text { Libidibia ferrea var. } \\
\text { ferrea }\end{array}$ & $\begin{array}{l}\text { Legume } \\
\text { bacóide }\end{array}$ & Longo & - & + & Invaginado & $\begin{array}{l}\text { Diferenciada } \\
\text { em eófilos }\end{array}$ & Zoocórica & Fruto \\
\hline $\begin{array}{l}\text { Poincianella } \\
\text { gardneriana }\end{array}$ & Legume & Curto & - & + & Invaginado & $\begin{array}{l}\text { Diferenciada } \\
\text { em eófilos }\end{array}$ & Autocórica & Semente \\
\hline $\begin{array}{l}\text { Chamaecrista } \\
\text { amiciella }\end{array}$ & Legume & Curto & - & + & Invaginado & Indiferencida & Autocórica & Semente \\
\hline $\begin{array}{l}\text { Chamaecrista } \\
\text { duckeana }\end{array}$ & Legume & Curto & - & - & Invaginado & $\begin{array}{l}\text { Diferenciada } \\
\text { em eófilos }\end{array}$ & Autocórica & Semente \\
\hline $\begin{array}{l}\text { Senna macranthera } \\
\text { var. pudibunda }\end{array}$ & $\begin{array}{l}\text { Legume } \\
\text { bacóide }\end{array}$ & Curto & - & + & Invaginado & Indiferencida & Zoocórica & Fruto \\
\hline Senna trachypus & Legume & Longo & Sub-mediano & + & Invaginado & Indiferencida & Autocórica & Semente \\
\hline $\begin{array}{l}\text { Senegalia } \\
\text { piauhiensis }\end{array}$ & Legume & Longo & Apical-basal & - & Criptorradicular & $\begin{array}{l}\text { Diferenciada } \\
\text { em eófilos }\end{array}$ & Autocórica & Semente \\
\hline
\end{tabular}




\begin{tabular}{|c|c|c|c|c|c|c|c|c|}
\hline Espécie & $\begin{array}{c}\text { Fruto } \\
\text { (Barroso et } \\
\text { al. 1999) }\end{array}$ & Funículo & Pleurograma & Endosperma & Embrião & Plúmula & $\begin{array}{l}\text { Síndrome de } \\
\text { dispersão }\end{array}$ & Diásporo \\
\hline $\begin{array}{l}\text { Calliandra } \\
\text { depauperata }\end{array}$ & Legume & Curto & Apical-basal & - & $\begin{array}{l}\text { Parcialmente } \\
\text { criptorradicular }\end{array}$ & $\begin{array}{l}\text { Diferenciada } \\
\text { em eófilos }\end{array}$ & Autocórica & Semente \\
\hline $\begin{array}{l}\text { Pithecellobium } \\
\text { diversifolium }\end{array}$ & Legume & Longo & Apical-basal & - & Criptorradicular & $\begin{array}{l}\text { Diferenciada } \\
\text { em eófilos }\end{array}$ & Zoocórica & Semente \\
\hline $\begin{array}{l}\text { Mimosa } \\
\text { ophthalmocentra }\end{array}$ & Craspédio & Longo & Apical-basal & + & Invaginado & Indiferencida & Autocórica & $\begin{array}{c}\text { Artículo } \\
\text { monospérmico }\end{array}$ \\
\hline $\begin{array}{l}\text { Parapiptadenia } \\
\text { zehntneri }\end{array}$ & Legume & Longo & - & + & $\begin{array}{l}\text { Parcialmente } \\
\text { invaginado }\end{array}$ & $\begin{array}{l}\text { Diferenciada } \\
\text { em eófilos }\end{array}$ & Anemocórica & Semente \\
\hline $\begin{array}{l}\text { Piptadenia } \\
\text { stipulacea }\end{array}$ & Legume & Longo & Mediano & + & Invaginado & $\begin{array}{l}\text { Diferenciada } \\
\text { em eófilos }\end{array}$ & Autocórica & Semente \\
\hline $\begin{array}{l}\text { Dahlstedtia } \\
\text { araripensis }\end{array}$ & $\begin{array}{l}\text { Legume } \\
\text { samaróide }\end{array}$ & Rudimentar & - & - & Papilionóide & $\begin{array}{l}\text { Diferenciada } \\
\text { em eófilos }\end{array}$ & Anemocórica & Fruto \\
\hline Dioclea grandiflora & $\begin{array}{l}\text { Legume } \\
\text { nucóide }\end{array}$ & Longo & - & - & Papilionóide & Indiferencida & Autocórica & $\begin{array}{l}\text { Fruto ou } \\
\text { semente }\end{array}$ \\
\hline $\begin{array}{l}\text { Luetzelburgia } \\
\text { auriculata }\end{array}$ & Sâmara & Curto & - & - & Papilionóide & Indiferencida & Anemocórica & Fruto \\
\hline Trischidium molle & Legume & Curto & - & - & Papilionóide & $\begin{array}{l}\text { Diferenciada } \\
\text { em eófilos }\end{array}$ & Zoocórica & Semente \\
\hline
\end{tabular}

sementes dispersas pelo vento prevalecem em florestas secas, e que a dispersão por animais ganha maior importância em florestas úmidas (Gentry 1983).

Em relação à caracterização morfológica da plúmula, Lima (1985), Gunn (1986) e Kirkbride et al. (2003) citaram o mesmo padrão para os gêneros estudados neste trabalho, entretanto em relação à Parapiptadenia Gunn (1984) descreveu a plúmula como rudimentar. As espécies de Parapiptadenia analisadas por Gunn (1984) foram as mesmas estudadas por Lima (1985), no entanto esta última autora descreveu a plúmula diferenciada em eófilos para as espécies deste gênero, o que se confirmou no presente trabalho.

O tratamento sobre as plúmulas foi um importante subsídio à identificação de indivíduos em frutificação. A maioria destas plantas são árvores de grande porte ou arbustos que ocorrem em populações amplamente distribuídas na área de estudo. Assim como o sucesso na germinação e estabelecimento de plântulas está associado ao tamanho e quantidade de reservas da semente (Kitajima \& Fenner 2000) é bastante provável que o grau de diferenciação da plúmula seja mais um aspecto a ser investigado, em relação ao seu papel no êxito do estabelecimento de plântulas.

\section{Agradecimentos}

Os autores agradecem aos colegas do Laboratório de Morfotaxonomia Vegetal da UFPE, pela ajuda nas coletas; ao Dr. João Iganci e ao designer Rodrigo Aguiar, pelas ilustrações; à CAPES, pela bolsa de Mestrado concedida à primeira autora e ao PPGBV/UFPE e à Fundação $\mathrm{O}$ Boticário de Proteção à Natureza, pelo financiamento das viagens de campo.

\section{Referências}

Alves, J. J. A.; Araújo, M. A.; Nascimento, S. S. 2009. Degradação da caatinga: uma investigação ecogeográfica. Revista Caatinga 22: 126-135.

Barroso, G.M.; Morim, M.P.; Peixoto, A.L. \& Ichaso, C.L.F. 1999. Frutos e sementes: morfologia aplicada à sistemática de dicotiledôneas. Vol. 2. Imprensa Universitária, Viçosa. 377p.

Bentham, G. 1875. Revision of suborder Mimoseae. Transactions of the Linnaean Society 30: 335-664.

Boelcke, O. 1946. Estudo morfológico de las semillas de Leguminosas Mimosoideas y Caesalpinioideas de interés agronómico de la Argentina. Darwiniana 7: 240-321.

Bravato, M. 1974. Estudio morfologico de frutos e semillas de las Mimosoideae (Leguminosae) de Venezuela. Acta Botanica Venezuelica 9: 317-361.

Burkart, A. 1943. Las leguminosas argentinas. Acme Agency, Buenos Aires. 590 p. 
Cardoso, D.B.O.S. \& Queiroz, L.P. 2007. Diversidade de Leguminosae nas caatingas de Tucano, BA: Implicações para a fitogeografia do semiárido do Nordeste do Brasil. Rodriguésia 58: 379-371.

Córdula, E.; Queiroz, L.P. \& Alves, M. 2008. Checklist da flora de Mirandiba, Pernambuco: Leguminosae. Rodriguésia 59: 597-602.

Córdula, E.; Queiroz, L.P. \& Alves, M. 2009. Leguminosae. In: Alves, M.; Araújo, M.F.; Maciel, J.R. \& Martins, S. (orgs.). Flora de Mirandiba. Associação Plantas do Nordeste, Recife. Pp. 183-233.

Corner, E. J. H. 1976. The seeds of dicotyledons. Vol. 1. University Press, Cambridge. 558p.

Duke, J. A. 1969. On tropical tree seedlings I. Seeds, seedlings, systems and systematics. Annals of Missouri Botanical Garden 56: 125 - 161.

Gentry, A. H. 1983. Dispersal ecology and diversity in neotropical forest communities. Sonderband Naturwissenschaftlicher Verein Hamburg 7: 303-314.

Gunn, C.R. 1984. Fruits and seeds of genera in the subfamily Mimosoideae (Fabaceae). U.S. Department of Agriculture, Technical Bulletin $n^{\circ}$ 1681. 194p.

Gunn, C.R. 1986. Fruits and seeds of genera in the subfamily Caesalpinioideae (Fabaceae). U.S. Department of Agriculture. Technical Bulletin $n^{\circ}$ 1755. 408p.

Harris, J. \& Harris, M. 2000. Plant identification terminology, an illustrated glossary. Spring Lake Publishing, Spring Lake. 216p.

Kirkbride, J.H.; Gunn, C.R.J. \& Weitzman, A.L. 2003. Fruits and seeds of genera in the subfamily Faboideae (Fabaceae). U.S. Department of Agriculture, Technical Bulletin $n^{\circ} 1890$. Vols. 1 e 2. 1208p.

Kitajima, K. \& Fenner, M. 2000. Ecology of seedling regeneration. In: Fenner, M. (ed.). Seeds. The ecology of regeneration in plant communities. Pp. 331-359. CABI Publishing, Wallingford. 410p.

Lewis, G. P.; Schrire, B.; Mackinder, B. \& Lock, M. 2005. Legumes of the world. Royal Botanic Gardens, Kew. 592 p.

Lima, H. C. 1990. Tribo Dalbergieae (LeguminosaePapilionoideae). Morfologia dos frutos, sementes e plântulas e sua aplicação na sistemática. Arquivos do Jardim Botânico do Rio de Janeiro 30: 1-42.

Lima, H.C.; Queiroz, L.P.; Morim, M.P.; Souza, V.C.; Dutra, V.F.; Bortoluzzi, R.L.C.; Iganci, J.R.V.; Fortunato, R.H.; Vaz, A.M.S.F.; Souza, E.R.; Filardi, F.L.R.; Valls, J.F.M.; Garcia, F.C.P.; Fernandes, J.M.; Martins-da-Silva, R.C.V.; Perez, A.P.F.; Mansano, V.F.; Miotto, S.T.S.; Tozzi, A.M.G.A.; Meireles, J.E.; Lima, L.C.P. ; Oliveira, M.L.A.A.; Flores, A.S.; Torke, B.M.; Pinto, R.B.; Lewis, G.P.; Barros, M.J.F.; Schütz, R.; Pennington, T.; Klitgaard, B.B.; Rando,
J.G.; Scalon, V.R.; Cardoso, D.B.O.S.; Costa, L.C.; Silva, M.J.; Moura, T.M.; Barros, L.A.V.; Silva, M.C.R.; Queiroz, R.T.; Sartori, A.L.B.; Camargo, R.A. \& Lima, I.B. 2013. Fabaceae. In: Lista de espécies da flora do Brasil. Jardim Botânico do Rio de Janeiro. Disponível em $<$ http://floradobrasil.jbrj. gov.br/jabot/floradobrasil/FB115>. Acesso em 18 Mai 2013.

Lima, M.P.M. 1985. Morfologia dos frutos e sementes dos gêneros da tribo Mimoseae (Leguminosae Mimosoideae), aplicada à sistemática. Rodriguésia 37: 53-78.

Meireles, J.E. \& Tozzi, A.M.G.A. 2008. Seed and embryo morphology of Poecilanthe (Fabaceae, Papilionoideae, Brongniartieae). Botanical Journal of the Linnean Society 158: 249-256.

MMA. 2002. Avaliação e ações prioritárias para a conservação da biodiversidade da caatinga. Por: UFPE/Fade/Conservation Internacional do Brasil/ Fundação Biodiversitas/Semi-Árido, Brasília. 40p.

Oliveira, D.M.T. 1999. Morfo-anatomia do embrião de leguminosas arbóreas nativas. Revista Brasileira de Botânica 22: 413-427.

Prado, D.E. 2003. As caatingas da América do Sul. In: Leal, I.R.; Tabarelli, M. \& Silva, J.M.C. (eds.). Ecologia e conservação da caatinga. Ed. Universitária da UFPE, Recife. Pp. 3-73.

Queiroz, L.P. 2002. Distribuição de espécies de Leguminosae na caatinga. In: Sampaio, E. V. S. B.; Giulietti, A.M.; Virgínio, J. \& Gamarra-Rojas, C.F.L. (eds.). Vegetação e flora da caatinga. APNE/ CNIP, Recife. $176 \mathrm{p}$.

Queiroz, L.P. 2006. The Brazilian caatinga: phytogeographical patterns inferred from distribution data of the Leguminosae. In: Pennington, R.T.; Lewis, G.P. \& Ratter, J.A. (eds.). Neotropical savannas and dry forests: plant diversity, biogeography, and conservation. Taylor \& Francis Crc-Press, Boca Raton. Pp. 113-149.

Queiroz, L.P. 2009. Leguminosas da Caatinga. Universidade Estadual de Feira de Santana, Feira de Santana. 443p.

Roth, I. 1977. Fruits of Angiosperms, Handbuch der Pflanzenanatomie. Encyclopedia of plants anatomy. Part 10. Gebruder Borntraeger, Berlin. 676p.

Silva, M.J.; Queiroz, L.P. ; Tozzi, A.M.G.A. ; Lewis, G.P. \& Souza, A.P . 2012. Phylogeny and biogeography of Lonchocarpus sensu lato and its allies in the tribe Millettieae (Leguminosae, Papilionoideae). Taxon 61: 93-108.

Stern, W. T. 1980. Botanical Latin. David \& Charles Publ., London. 556p.

Van Der Pijl, L. 1982. Principles of dispersal in higher plants. Springer-Verlag, Berlim. 162p. 